\title{
COVID-19: Journey so far and Deep Insight Using Crowdsourced Data in India
}

\author{
I. Tyagi ${ }^{1}$, Y. Mahfooz ${ }^{2}$, Mohd Kashif ${ }^{1}$ and A. Anjum ${ }^{1}$ * \\ ${ }^{1}$ Galgotias College of Engineering and Technology, Knowledge Park II, Greater Noida, Uttar Pradesh 201306, \\ India \\ ${ }^{2}$ Department of Marketing, College of Business Administration, King Saud University, P. O. Box 71115, \\ Riyadh 11587, Kingdom of Saudi Arabia
}

Received: 04 April 2020 / Accepted: 18 November 2020 / Published online: 3 January 2021

(C) Metrology Society of India 2021

\begin{abstract}
The aim of this study is to assemble the data and reflect the epidemiological statistics required as well as apply mathematical prototypical approach of the new outbreak that cover all perspectives of the facts and figures as of August 08, 2020, and thereby suggest the direction of the forthcoming epidemic situation in India for all policy makers. The outburst of the new fatal strain of coronavirus from an animal-to-human fall over in China has infected at least 204 countries as well as territories throughout the world. As of April 03, 2020, almost 972,303 confirmed cases and 50,321 deaths have been reported across the world due to severe acute respiratory syndrome coronavirus-2 (SARS-CoV-2) that attained a huge elevation to $19.3 \times 10^{6}$ confirmed cases on August 08, 2020, of which India contributes a major part of $2.09 \times 10^{6}$ confirmed cases. It is the first neoliberal virus that easily encompasses its danger chiefly to easily susceptible including the malnutrition, the ill, and old people. As the world struggles with pandemic, India with its second largest population of more than 1.3 billion people in the world is likely to have many more cases than the numbers currently being reported. This has put numerous thousand individuals under observation in the country due to clinical symptoms, recent travel to China, Italy, Iran, and concordant entries in the relevant tailing surveys. The novelty of this approach is to rely on the exclusive source of official data, for social media and daily tracking of news reports in India that collected and curated the pertinent information.
\end{abstract}

Keywords: Coronavirus; COVID-19; Outburst; Pandemic; India

\section{Introduction}

The world today has witnessed an emergency situation due to increasing widespread of a fatal severe acute respiratory syndrome coronavirus-2 (SARS-CoV-2) since December 2019. The virus has proved to be much more fatal than the influenza pandemic in 1918 that was counted as the deadliest event witnessed by the human history that proved to be a reason to death of more than 50 million people. However, the pandemic stood as a yardstick for more than a century with reference to which all other epidemics and related emergencies have been compared and measured. The capital of Hubei Province in China, Wuhan, came to be known as the center of an outburst of peculiar, incurable

*Corresponding author, E-mail: ansaranjum_a@rediffmail.com problem of pneumonia the cause to which could not be understood by the doctors. However, the scientists in the early January 2020 isolated a novel coronavirus, severe acute respiratory syndrome coronavirus-2 (SARS-CoV-2) from samples of the patients suffering with such pneumonia [1]. This virus was later labeled as coronavirus disease 2019 (COVID-19) in February 2020, by World Health Organization [2]. The outburst of COVID-19 has been reported to originate from a zoonotic transmission from a large market of seafood and wild animals. The virus has been exported to at least 140 countries, till date (as of March 19, 2020) out of which as many as 11 European countries are among the top 15 are reported to possess largest number of cases with the infection of coronavirus in the world. Evidently, the efficient transmission from one person to another in hospital as well as among family members has also been reported [3]. The WHO has declared the emergency situation due to COVID-19 as a 
Public Health Emergency of International concern. However, if public health efforts become incapable of controlling the widespread of virus, human race is expected to shortly witness the emergence of a mortal worldwide pandemic.

Coronavirus is a microscopic pathogen with its genetic material (RNA) that is dispersed largely among humans, birds, and other mammals. It is known to cause various disorders including respiratory, enteric, hepatic, and neurologic diseases $[4,5]$. There are six strains of coronavirus known to cause human disease out of which four viruses229E, OC43, NL63, and HKUI-are predominant and usually show symptoms of common cold in immune competent individuals [6]. Besides, the other two other strains, namely severe acute respiratory syndrome coronavirus (SARS-CoV) and Middle East respiratory syndrome coronavirus (MERS-CoV), have been associated with sometimes mortal illness [7]. SARS-CoV is known to be the causative agent of the severe acute respiratory syndrome outbreaks in 2002 and 2003 in Guangdong Province, China, that infected around 8,000 patients and claimed 800 lives $[8,9]$. Though zoonotic in origin, the present strain of severe acute respiratory syndrome coronavirus-2 (SARS$\mathrm{CoV}-2$ ) is the new and seventh strain of the family of corona virus that is capable of causing infection in humans [10].

The present paper discusses about the journey of severe acute respiratory syndrome coronavirus-2 (SARS-CoV-2) to India and its growth pattern from the day of its inception. The purpose of this article is to prepare a cumulative data of the prevailing research and aggregate all the significant data so as to permit the researchers to make an outcome of the data interpreted and published so as to perform an early research on COVID-19 upcoming outburst. Different statistical details have been used to study the pattern of the growth of infection in the country, and its various perspectives are discussed.

\section{Spreading Trend of Virus}

The infection of the virus encompasses different types of illness including asymptotic infection, infection of upper respiratory tract that spreads through the tract and enters lungs to cause severe pneumonia leading to failure of the respiratory system and hence may even lead to death as also reported in several cases of pneumonia cases hospitalized in Wuhan [11, 12]. Thus, during first 60 days of the outbreak in China, the rapid spread of COVID-19 took place throughout China causing different degree of ailment. Many people reported the illness with no fever while in some cases even abnormal radiologic findings were also not reported. Though the coronaviruses is actually large family of viruses that can lead to illness ranging from common cold to acute respiratory syndromes, but according to WHO severe acute respiratory syndrome coronavirus-2 (SARS-CoV-2) has not been traced earlier and shows distinct respiratory symptoms including fever, cough, and shortness of breath. This is the reason that coronavirus epidemic has been acknowledged as a worldwide health emergency by WHO.

Severe acute respiratory syndrome coronavirus-2 (SARS-CoV-2) not only affects the elderly people with prevailing problems of health but also healthy adults. The data available up till now suggest that the case mortality threat caused due to virus is around $1 \%$ that makes it many times more dangerous than the seasonal influenza. This places the COVID-19 to lie amid the influenza pandemic of $1957(0.6 \%)$ and the pandemic of 1918 due to influenza (2\%) [13]. Also, the transmittance of COVID-19 is very efficient, and according to the studies reported, a person infected with the virus can easily spread it to at least two or three others contributing to the spread at an exponential rate of increase. The reports of the spread of virus show strong indication of its transmittance through people with mild illness or presymptomatic [14]. This suggests that the disease shall substantiate to be much more difficult task to handle than the MERS or SARS, which presented less widespread and only through symptomatic people. However, the severity of virus has already been observed by the increased number of cases reported (10 times more cases as SARS) during one-fourth of the time period.

\section{Method and Data Compilation}

We monitored the updates on mohfw.gov.in and covid19india.org very closely between January 30, 2020, and August 08, 2020, to abstract the key information of individual patients and the origin of COVID-19 at national as well as state level and the reports of daily count of cases registered.

A list of internationally exported cases of the virus was also compiled from news media sources (Economic times, and India today), national government websites, and WHO situation reports. The availability of datasets is significant during early stages of an outbreak so as to encourage the possible analytical efforts by researchers and provide strong evidence to make interpolations. The paper therefore focuses on the pattern of drift toward epidemiology of COVID-19 in India, assessing delays of the spread of awareness, and number of cases with foreign travel history. All data were made publicly available in real time. 


\subsection{First Case in India}

The coronavirus has spread globally and WHO reports the first positive case of COVID-19 in India on January 30, 2020 , in the state of Kerala. At the same time, China was sailing with 7736 confirmed cases on the virus, as per the WHO records [15]. As of January 30, 2020, the cases of COVID-19 had been confirmed in 20 countries and territories outside of China. The transmission of virus from one human to another is established by the spread in Germany, Vietnam, and Japan. The onset of COVID-19 in India was reported in Thrissur District of Kerala. The carrier is an Indian student at Wuhan University, China, who presented an urgent clinical care with symptoms of the virus and was immediately admitted to the hospital on January 27, 2020.

The second case of the virus was reported on February 2, 2020, in the Alphuzha, Kerala. The patient was also a student in China and had come to hometown during vacations. Consecutively, the third case was reported on February 3, 2020, in Kasaragod District of Kerala, India, following which the local government declared a state of emergency. Adding a trail to it, in not more than 41 days of the report of the first COVID-19 case in India there were 50 more confirmed cases that added to the list. This evidently supports the view that the virus can spread to more than two secondary cases for every primary case as shown in Fig. 1.

An analysis of the statistical understanding of the spread of first 50 cases in India reflects the following major perspectives:

1. The travel history to any of the affected country has played a major role that can be agreed upon from the subsequent data:

- The first 39 cases of the COVID-19 had foreign travel history.

- Of the first 39 cases reported, 23 cases had a travel history of Italy, including the 16 Italian nationals who tested positive in Jaipur, India.

- Four confirmed COVID-19 cases had a travel history to Iran as well and to the USA.

- Three virus confirmed cases had a travel history to China.

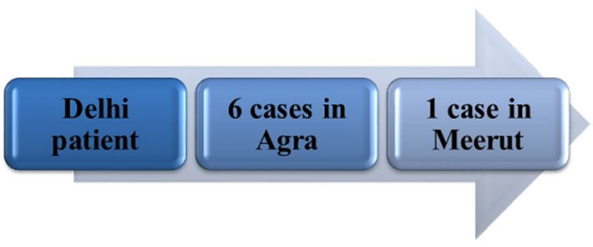

Fig. 1 Representation of COVID-19 transmitting to more than two secondary cases for every primary case (Delhi patient)
- Three confirmed cases had been traveling to Dubai.

- One affected patient had a travel history of Oman and one of Thailand and Singapore (Fig. 2).

2. The virus is not only capable of affecting the old age people but also the young generation as is reflected from the virus confirmation report of an infant. Out of all the first 50 cases in India, the youngest case of COVID-19 was a three-year-old girl reported from Ernakulum District of Kerala.

3. The COVID-19 is capable of diffusing through local transmission as well. The remaining 11 cases contracted the infection through local transmission, and the hierarchy of their transmission is reflected in Fig. 2. In these cases, District Meerut represents landmark of being the first case of third-level transmission in humans.

India reported six new cases of COVID-19 on March 10 from Maharashtra and Karnataka. These states had so far been untouched by the outbreak of coronavirus [16]. Thus, 13 states and Union territories in India had then reported at least one COVID-19 case including Kerala, Karnataka, Maharashtra, Tamil Nadu, Telangana, Uttar Pradesh, Delhi, Haryana, Rajasthan, Punjab, Jammu and Kashmir, and Ladakh.

A confirmed COVID-19 case reported in Delhi led to quarantine of six of his family members whom he met in Agra at a hospital in Delhi. These cases were detected with "high viral load" during sample testing in Agra. It is only in a span of four days two new confirmed COVID-19 were reported in Kerala that compelled the local government to declare a state of emergency on February 3, 2020. Almost 3400 people suspected to have come in contact with them were also put in quarantines and observed for coronavirusrelated symptoms.

\subsection{Initial Stages of COVID-19 and its Epidemiology Trend}

To the best of our knowledge, this article is the first study on inception of COVID-19 in India and its spread that uses crowd sourced data that become the added assessment of this study. The early information and analysis of data were taken mainly from the Situation reports issued by WHO, government online sources, and the daily reports from newsletters, India. Starting from the first case reported in the country to the drastic increase in number of cases lately, we need to consider different stages of the spread of virus including:

Stage I It includes the imported cases through the travelers who had traveled to virus-hit foreign countries and have now come back to India. 

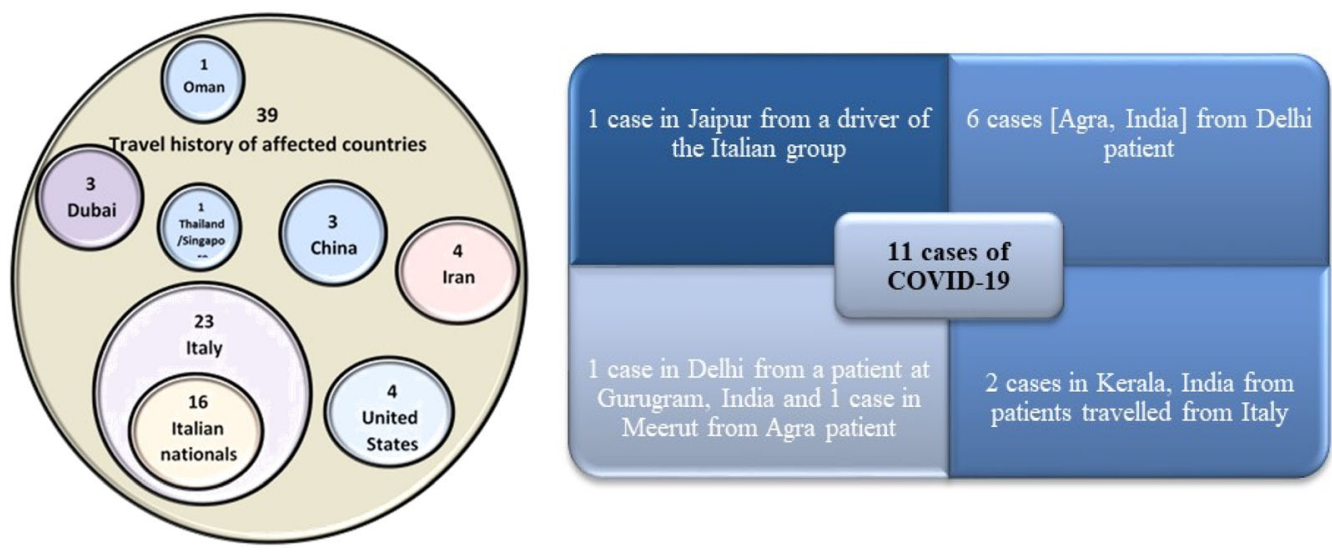

Fig. 2 Transmission of COVID-19 to first 39 cases reported and its secondary transmission in India

Stage II It includes the local transmission cases that have come in contact with the patients possessing a travel history.

Stage III It includes the transference of virus through community in which the patient has not been exposed to any infected person or one who has traveled to any of the affected countries tests positive. This stage is a very crucial stage as a large number of people get affected when community transmission takes place.

Stage IV This is the last and also the worst stage in which the disease takes the shape of an epidemic with no clear end point. It is the epidemic stage and could be lately seen in China and Italy.

The first stage of COVID-19 in India started with positive clinical report of an Indian student from Wuhan. The total number of cases in this stage was below 100. However, in March India entered second stage of transmission when the first Delhi man from Europe infected six people in Agra and made a start to local transmission as shown in Fig. 2. A statistical study of the data from Ministry of Health and Welfare, Government of India, shows an exponential growth in number of infected person after March 04, 2020, as shown in Fig. 3 [17]. This can be understood from the increase in number of confirmed cases from 28 on March 04, 2020, to 107 on March 14, 2020. Besides tailing the number of confirmed cases, the country reported its first death due to COVID-19 on the same day. The death reported of a 76-year-old male from Karnataka and 68-year-old female from Delhi, both possessed comorbidities [18]. The highest infection rate during first eight weeks of inception of COVID-19 in the country was observed in Maharashtra on March 22, 2020 [9.45 AM], with sudden jump in confirmed cases from 60 to 74 cases in the next two hours only [19]. This increased the overall number of recognized cases of COVID-19 to 360 on March 22, 2020 (18:30 IST) [20].

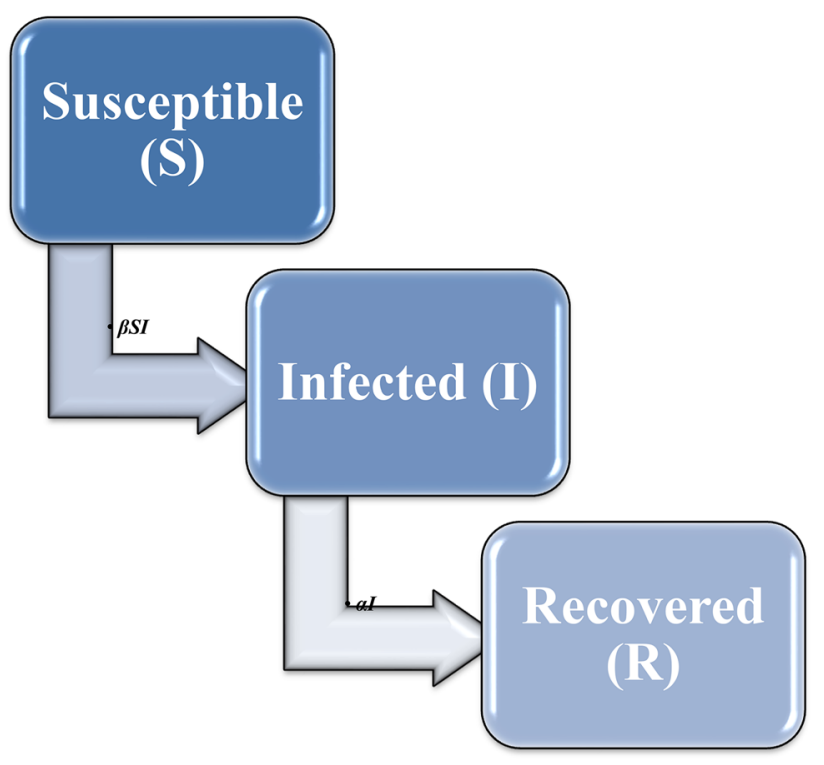

Fig. 3 Transmission of virus COVID-19 in different classes $(S, I$ \& R)

India entered an intermediate phase amidst Stage two and Stage three of the spread of COVID-19 near April 03, 2020 , with an average growth factor is 1.5 which implies that the country had onset its movement toward exponential part. The number of confirmed cases of the country reached 40,263 within a span of one month as on May 03, 2020 , that further hopped to $2,07,615$ on June 03,2020 , an increase of 1,67,352 confirmed cases in one month across the country. This points toward a steep rise in growth factor of 5.0 on March 08, 2020, and then, a decrease to 1.86 achieved on April 13, 2020, as also depicted by a steep rise in logarithmic curve of Fig. 5. The monthly growth rate of COVID-19 was observed to be 5.2 in May 03 that decreased to 3.58 on June 03, 2020, and then further decreased to 2.5 on August 03, 2020. 
The SIR Epidemic Mode (Susceptible, Infectious, Recovered) as shown in Fig. 3 is a simple classical model that describes the dynamics of directly transmitted virus with interaction among susceptible, infected, and recovered nodes in population.

The schematic diagram shown in Fig. 3 for the flow of virus among population model is represented as in Eq. 1: where $\beta$ is the rate of contact and $\alpha$ is the rate of transmission of virus from class $I$ to class $R$. Here the flow of virus is from class $S$ to class $I$ and class $I$ to class $R$.

The system of differential equations for this model is

$\frac{\mathrm{d} S}{\mathrm{~d} t}=-\beta S I$
$\frac{\mathrm{d} I}{\mathrm{~d} t}=\beta S I-\alpha I$
$\frac{\mathrm{d} R}{\mathrm{~d} t}=\alpha I$

The basic reproduction number $R_{0}$ for this model is $R_{0}=\beta / \alpha$.

Using method of Least Square, the normal equations to fit the second degree parabola of the form: $y=a+b x+$ $c x^{2}$ to the real data, to study the pattern of parabolic curve to find the values of $a, b$, and $c$ (Fig. 4).

$x=$ independent variable $=$ no. of days $y=$ dependent variable $=$ no. of confirmed cases

$$
\begin{aligned}
& \sum y=n a+b \sum x+c \sum x^{2} \\
& \sum x y=a \sum x+b \sum x^{2}+c \sum x^{3} \\
& \sum x^{2} y=a \sum x^{2}+b \sum x^{3}+c \sum x^{4}
\end{aligned}
$$

The value of growth factor shows that new infections are expected to explode exponentially, and hence, flattening of the curve is yet to approach. This could imply that there are orders of magnitude of growth to come in future days.

$y=18.866+66.1576 x-4.3333 x^{2}$

Even with the most perfectly pernicious of the model

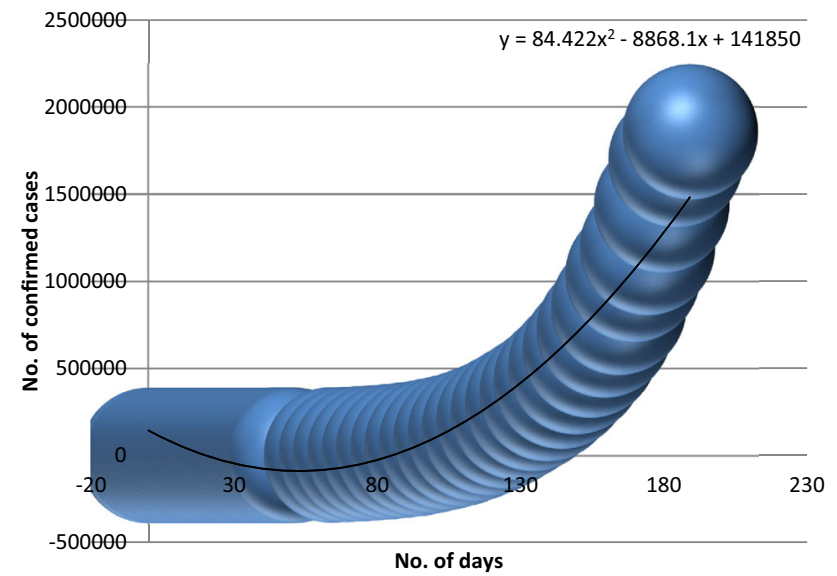

Fig. 4 Regression curve of number of confirmed cases in India wherein everyday an infected person is exposed to the random number of people, at some places most of the people would already be sick and so cannot be counted into cases. The statistical analysis of the data shows that as of now, the mean value of $549(\mathrm{SD}=699, n=32)$ has been attained on March 24, 2020, in the eighth week of inception of virus into the country. The number of new cases on a given day can be given by Eqs. (5) and (6).

$\Delta N_{d}=E \times P \times N_{d}$
Or, $\quad N_{d+1}=(1+E P) N_{d}$

where $E=$ average number of people someone exposed each day to an infected person, $P=$ probability of each exposure to convert to a new infection case.

The condition shown in Eq. (5) is evidently observed by the logarithmic curves as shown in Fig. 5. The state-wise spread of COVID-19 as on August 08, 2020, is shown in Table 1 that reflects a total of 619088 active cases in the country as compared to April 03, 2020, with total 2301 confirmed cases of COVID-19, out of which 49 confirmed cases are foreign nationals.

A close analysis of the total confirmed cases in India shows a substantial number belonging to five states only including Andhra Pradesh, Maharashtra, Delhi, Kerala, Uttar Pradesh, and Tamil Nadu. This accounts to the possession of big share of $57 \%$ of all the confirmed cases being reported by these states only, and the reported mortality rate of the country as of April 03,2020 , is $2.5 \%(n=38)$ as shown in Fig. 5. A close analysis of the data shows Maharashtra reflecting an impulsive jump from 60 confirmed cases as on March 22, 2020 [9:45 IST], to 74 cases in the next two hours only [19]. This increased the total number of confirmed cases of COVID-19 of the country to 360 as on March 22, 2020 (18:30 IST) [20]. However, on April 03, 2020, the total number of confirmed cases rose to 2301 as represented in Fig. 4.

\subsection{Factors Affecting Epidemiology of COVID-19 in India}

\subsubsection{Rate of Recovery}

The data reported on April 03, 2020, show that out of the total confirmed cases reported in India 157 cases have shown recovery and hence discharged form hospital, but this covers the recovery rate of only $6.8 \%$ of the total confirmed cases. The recovery growth dipped from $8.1 \%$ as on April 01, 2020, to 6.8\% April 03, 2020, that reflects very slow rate of recovery of the patients, and hence, a vigorous attempt is required by health departments of the respective states so as to escalate the rate of recovery. Although the total number of states affected by the virus as on April 03, 
Table 1 State-wise COVID-19 confirmed cases reported in India as on August 08, 2020 [21]

\begin{tabular}{|c|c|c|c|c|}
\hline S. no. & Name of state/UT & Total active cases & No. of cases cured/discharged/migrated & No. of death \\
\hline 1 & Andaman and Nicobar Islands & 778 & 425 & 19 \\
\hline 2 & Andhra Pradesh & 84,654 & 120,464 & 1842 \\
\hline 3 & Arunachal Pradesh & 720 & 1326 & 3 \\
\hline 4 & Assam & 16,555 & 38,809 & 132 \\
\hline 5 & Bihar & 26,453 & 44,482 & 369 \\
\hline 6 & Chandigarh & 531 & 820 & 23 \\
\hline 7 & Chhattisgarh & 3002 & 8319 & 87 \\
\hline 8 & Dadra and Nagar Haveli and Daman and Diu & 421 & 1014 & 2 \\
\hline 9 & Delhi & 10,409 & 128,232 & 4082 \\
\hline 10 & Goa & 2282 & 5595 & 70 \\
\hline 11 & Gujarat & 14,443 & 51,720 & 2605 \\
\hline 12 & Haryana & 6143 & 33,444 & 467 \\
\hline 13 & Himachal Pradesh & 1182 & 1954 & 14 \\
\hline 14 & Jammu and Kashmir & 7260 & 16,218 & 449 \\
\hline 15 & Jharkhand & 8923 & 7391 & 151 \\
\hline 16 & Karnataka & 77,694 & 84,232 & 2998 \\
\hline 17 & Kerala & 12,451 & 19,147 & 102 \\
\hline 18 & Ladakh & 411 & 1194 & 9 \\
\hline 19 & Madhya Pradesh & 8715 & 27,621 & 962 \\
\hline 20 & Maharashtra & 145,889 & 327,281 & 17,092 \\
\hline 21 & Manipur & 1530 & 1926 & 10 \\
\hline 22 & Meghalaya & 590 & 411 & 5 \\
\hline 23 & Mizoram & 277 & 289 & 0 \\
\hline 24 & Nagaland & 1826 & 824 & 7 \\
\hline 25 & Odisha & 13,605 & 28,698 & 247 \\
\hline 26 & Puducherry & 1873 & 2914 & 75 \\
\hline 27 & Punjab & 7351 & 14,040 & 539 \\
\hline 28 & Rajasthan & 13,195 & 36,195 & 767 \\
\hline 29 & Sikkim & 447 & 406 & 1 \\
\hline 30 & Tamil Nadu & 52,759 & 227,575 & 4690 \\
\hline 31 & Telangana & 22,568 & 54,330 & 615 \\
\hline 32 & Tripura & 1878 & 4084 & 37 \\
\hline 33 & Uttarakhand & 3058 & 5731 & 112 \\
\hline 34 & Uttar Pradesh & 44,563 & 66,834 & 1981 \\
\hline 35 & West Bengal & 24,652 & 63,060 & 1954 \\
\hline Total & & 619,088 & $1,427,005$ & 42,518 \\
\hline
\end{tabular}

2020, was 29 only, the number of states and Union territories affected with the virus increased to 35 up till August 06, 2020, as shown in Fig. 6. This suggests a continuous spread of the disease throughout the country. The recovery of patients may be correlated with an increase in epidemic due to the immunity developed in the effected person after recovery from the virus. However, some cases show that due to low levels of antibodies developed in the blood of affected person the recurrence of disease in the affected person may occur after recovery thereby not playing any significant role in the number of increasing affected cases
[22]. The COVID-19 affected cases can maintain their immunity to SARS-CoV-2 for a period of two weeks only after their recovery from the virus. This can be correlated with the fact that with the increase in rate of recovery from the disease there is no appreciable decrease in number of confirmed cases and the spread of disease.

The early mobility data of 27 cases of COVID-19 in Delhi reflect that 21 of the affected cases had a travel history of outside the country. However, of the total cases reported, the 06 confirmed cases did not have any of the 

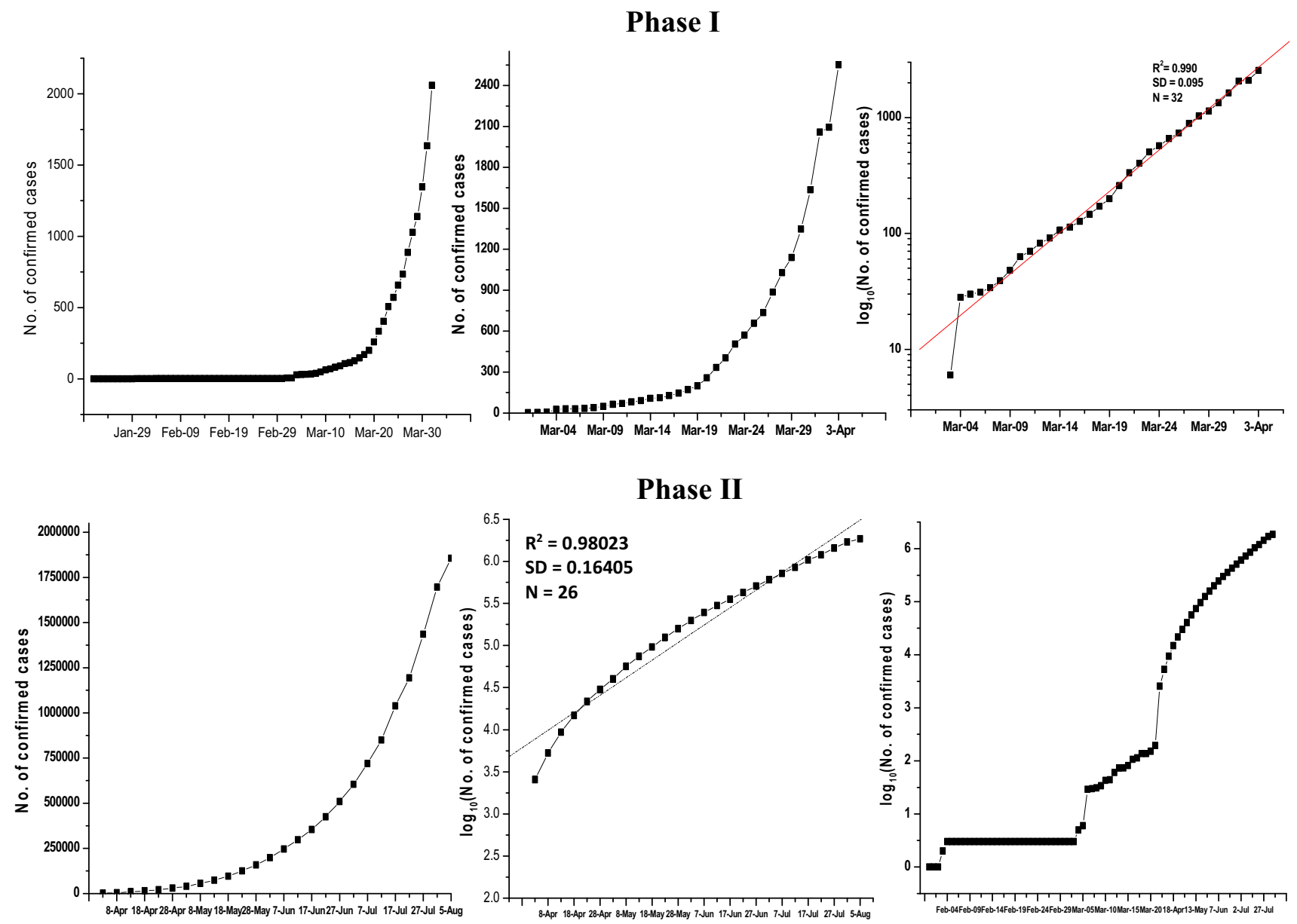

Fig. 5 Exponential growth pattern of COVID-19 confirmed cases in India in two phases

reported travel history, but the infection was transferred to them through 03 of the already infected areas.

The first death in the country was reported of a 76-yearold male from Karnataka followed by 68 -year-old female from Delhi, both with co-morbidities [18]. Also, the 68 -year-old woman was the first woman death of the second fatal case reported in India by COVID-19. She had contained the virus from his son who had in turn acquired the contagion during the trip abroad. The third case of death was reported of a 64-year-old man from the state of Maharashtra. He was reported to have a travel history to Dubai and is left behind with his ailing wife with diagnosed COVID-19.

The data reflect that from the day of inception of virus as the first reported case in the Kerala state of India the rate of growth of number of confirmed cases in the country was slow and total number of confirmed cases became almost constant for a period of 28 days, after which only one new confirmed case was reported. However, in fifth week of inception of the virus an increase in the number of confirmed cases gave a slight rise with the inclusion of two new confirmed cases added to the list. Listing on the 36th day of inception (March 06, 2020), a huge increase in the number of confirmed cases is observed that shows a steep rise in the curve. The graph shows 23 new confirmed cases reported in a span of one month and six days only. Another steep rise in the curve was observed in the eighth week of inception of virus making the total count of the number of confirmed cases as 2093 and recovered cases as 171 on April 02, 2020, as shown in Fig. 5. The first death due to COVID-19 reported after 42 days from the day of inception (a time gap of 6 weeks) of virus, the stage at which India was struggling with its 73 infected cases.

However, a significant increase in the rate of recovery was observed in Maharashtra, Delhi, Andhra Pradesh, and Bihar on August 06, 2020, as compared to the recovery rate on April 03, 2020. Delhi shows an appreciable recovery rate of $90 \%$ followed by recovery rate of $78 \%$ by Tamil Nadu as shown in Fig. 7. Thus, the interpretation from significant addition of large number of confirmed cases daily, during last 60 days, predicts that the present scenario creates a worrisome situation. The outbreak is seen to speedily move toward the first true pandemic challenge in the country as in the world that also fits well in the priority 

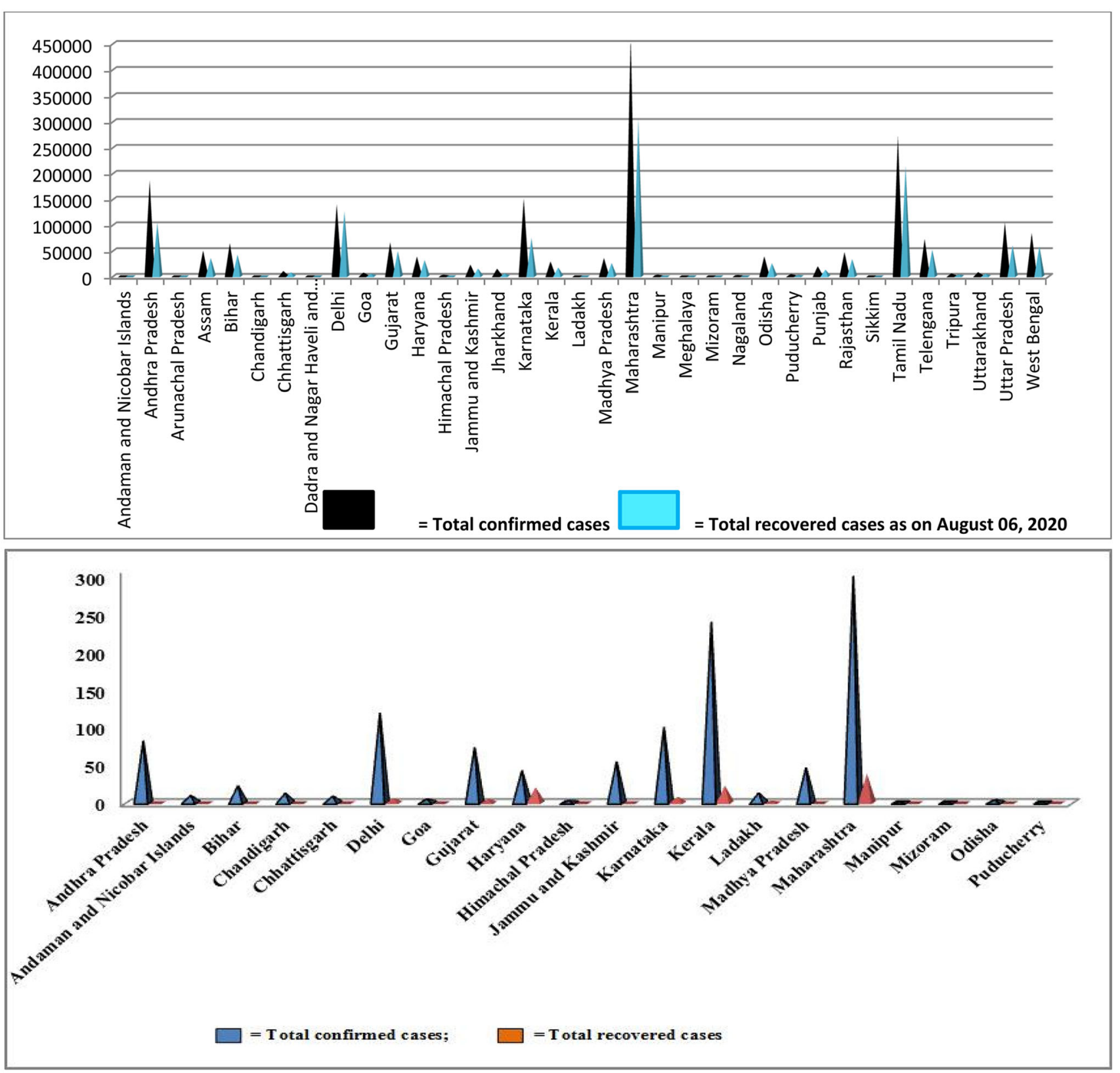

Fig. 6 Comparative representation of the total confirmed and recovered cases of different states of India (as on April 03, 2020, and August 06, 2020)

list of WHO. On March 16, 2020, India crossed the score of 100 confirmed COVID-19 cases which shows that only in just five days the approximate median of the total value was attained making it as $50 \%$ of all the cases. Owing to such situations in the country, we cannot deny that the health infrastructure of India needs to be improved.

According to the Indian Council of Medical Research (ICMR), India has reached the stage two of transmission with no sign of community transfer reported so far. However, a few cases have raised an alarm including a case of 20-year-old man from Delhi, a case in West Bengal, and another case $\mathrm{n}$ Pune that have shown positive results for the infection in spite of not having any travel history. Thus, the situation report has forced Government of India for immediate steps toward travel restrictions and forbidden entry of travelers from all countries as of now (Fig. 8).

\subsubsection{Environmental Factors}

The research studies so far suggest that the virus behaves similar to influenza that show reduced activity under hot and humid environment [23]. 

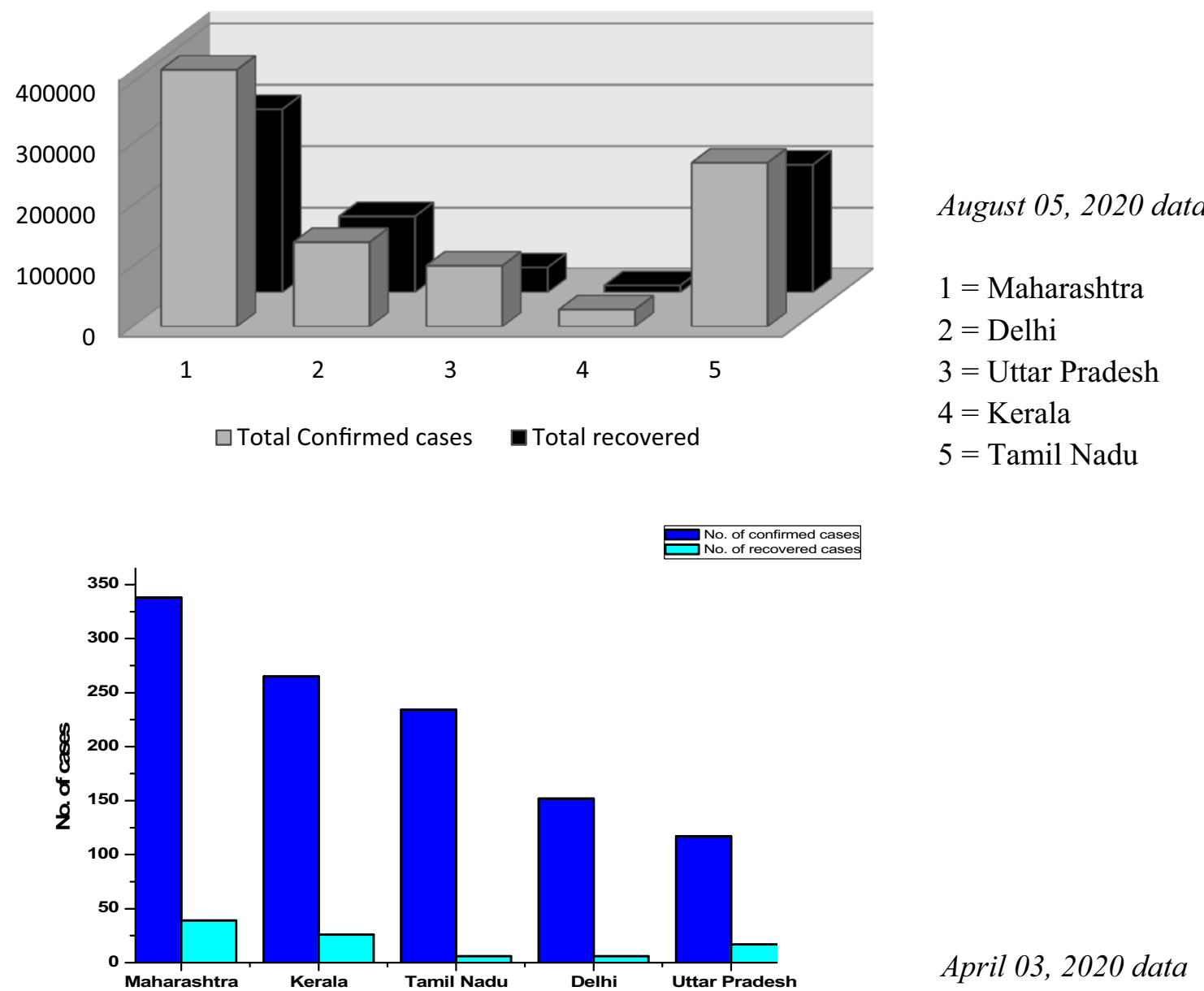

Fig. 7 Statistical representation of the number of confirmed cases and recovered cases as on August 05, 2020, and April 03, 2020)

Fig. 8 Representation of the comparison of confirmed and recovery of the countries with first confirmed case on January 30,2020

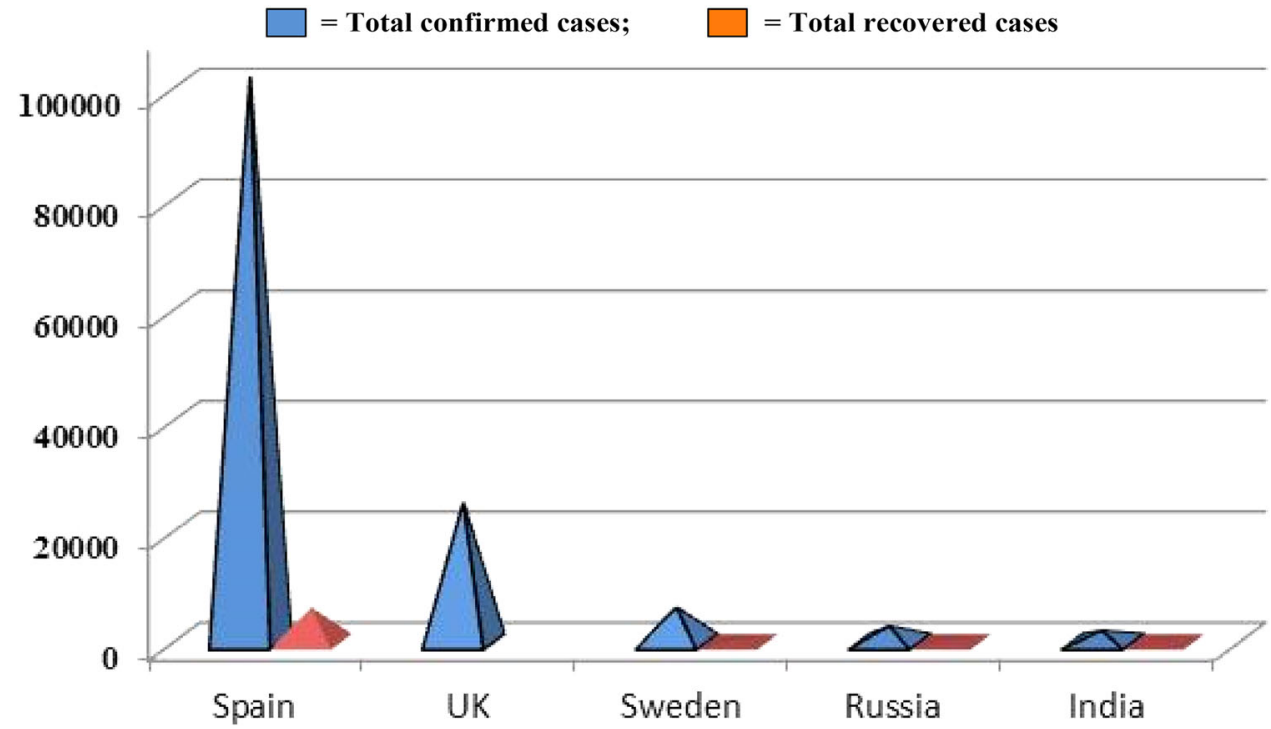

Latest laboratory and epidemiological data have been suggested that environmental factors may affect the spread of virus [24]. A study show that virus is stable at $4{ }^{\circ} \mathrm{C}$ but sensitive to heat and the survival rate of virus is shortened by $05 \mathrm{~min}$ at $70{ }^{\circ} \mathrm{C}$ [25]. Another environmental factor that affects the spread of virus is humidity wherein a relative 
humidity between 40 and $60 \%$ is known to contain the virus [26]. Temperature and relative humidity were both negatively related to the daily new cases up to some extent. A comparative study of growth factor with the temperature and relative humidity has suggested that Delhi and Uttar Pradesh which are having almost similar condition of temperature and relative humidity show decline in the growth factor of active cases from April to May due to increase in average temperature in both the states as shown in Fig. 9. Therefore, growth factor decreases drastically from 25.74 to 3.99 in Delhi while in case of Uttar Pradesh during the same time interval growth factor decreases from 24.7 to 1.78 . This decrease in growth factor continued in Delhi in the subsequent months of June and July despite of decrease in average temperature. This can be related to the increase in the relative humidity owing to the onset of monsoon during the months of June and July. Therefore, in Delhi the spread of virus restricted with hot and humid conditions. However, it is not the case with other states including Uttar Pradesh where we have seen increase in the growth factor in the month of July where average temperature is $35{ }^{\circ} \mathrm{C}$ and relative humidity is $70 \%$. The reason for such a decrease in growth factor in Delhi is the contribution of other factors including increased testing, tracing and isolation, and formation of micro-containment zone that led to drastic reduction in active cases.

In Maharashtra and Kerala, the temperature and relative humidity did not show appreciable change and are almost constant from April to July with an average temperature of $30-35{ }^{\circ} \mathrm{C}$ and relative humidity in the range of $70-80 \%$. In Maharashtra, growth factor decreases regularly from April to July which is in accordance with the studies that hot and humid conditions restricted the virus spread. However, in Kerala an increase in growth factor of virus spread is seen during the month of July despite the similar weather conditions as of Maharashtra. Tamil Nadu also observes a decline in growth factor regularly from April to July although temperature and relative humidity both decrease marginally.

India experiences monsoon period during the month of June-September due to which an increase in relative humidity is observed in most parts of the country, but growth factor is seen to deviate from trend in most part of the country. This is because relative humidity and temperature although play a significant role in spread of virus, but the situation can be avoided to get worse by taking into consideration of other factors including an increase in testing (From 4000 in April to around 400,000 in July), relaxation in lockdown conditions, interstate and intercity mobility of people, population density, and socioeconomic factors.

\subsubsection{Population Density}

A comparative study of the trend of active cases with respect to population density in Andhra Pradesh and Delhi shows that Andhra Pradesh has low population density (308 persons $/ \mathrm{Km}^{2}$ ) as compared to Delhi (11297 person/ $\mathrm{Km}^{2}$ ). Figure 10 shows that the number of active cases reported in Andhra Pradesh was found to be less than that reported in Delhi and the trend followed by them up till July 19, 2020, shows that the number of active cases is strongly correlated with the population density of the area. The state with low population density shows lesser extent of spread of the virus in the area.

However, after 139 days of the first active case in Andhra Pradesh the situation got reversed after July 19, 2020 , with increasing trend of 85486 active cases as compared to Delhi with 10,667 active cases as on August 09, 2020. But the high spike of number of active cases in Maharashtra shows no correlation when its low population density of 370 persons $/ \mathrm{km}^{2}$ is compared with the number of active cases in Delhi. Such disparity suggests that population density is not the only limiting factor in the transmission of COVID-19, but there are other factors also that determine the mechanism of the transport of the virus including socioeconomic factors, employment, transportation used by people, and environmental factors.

\section{Discussion and Conclusion}

The logarithmic curve of confirmed cases depicts that in the duration of 10 days the number of cases increased from 10 to 100 , and then, in next 14 days the number of cases increased from 100 to 1000 . This predicts that the number of confirmed cases tends to multiply by a factor of 10 after every 12 days on an average. The regression coefficient $\left(R^{2}\right)$ of 0.990 shows an appreciable good exponential fit of the figures available so far that further points toward the exponential growth of disease in near future. Based on the observations of data from the early outbreak in India from March 01-16, 2020, the mean basic reproduction number was 0.5 that gives a positive picture of the situation reflecting it to be not so alarming. If the comparison of growth factor of COVID-19 is made between India with Spain, both the countries reported their first case on the same day. The total number of confirmed cases in Spain as on April 01, 2020, is 117,710 that is a huge number as compared to India as of now that shows the growth rate in India is much slow as compared to Spain. This can be taken as India stands with doing much better then Spain as shown 


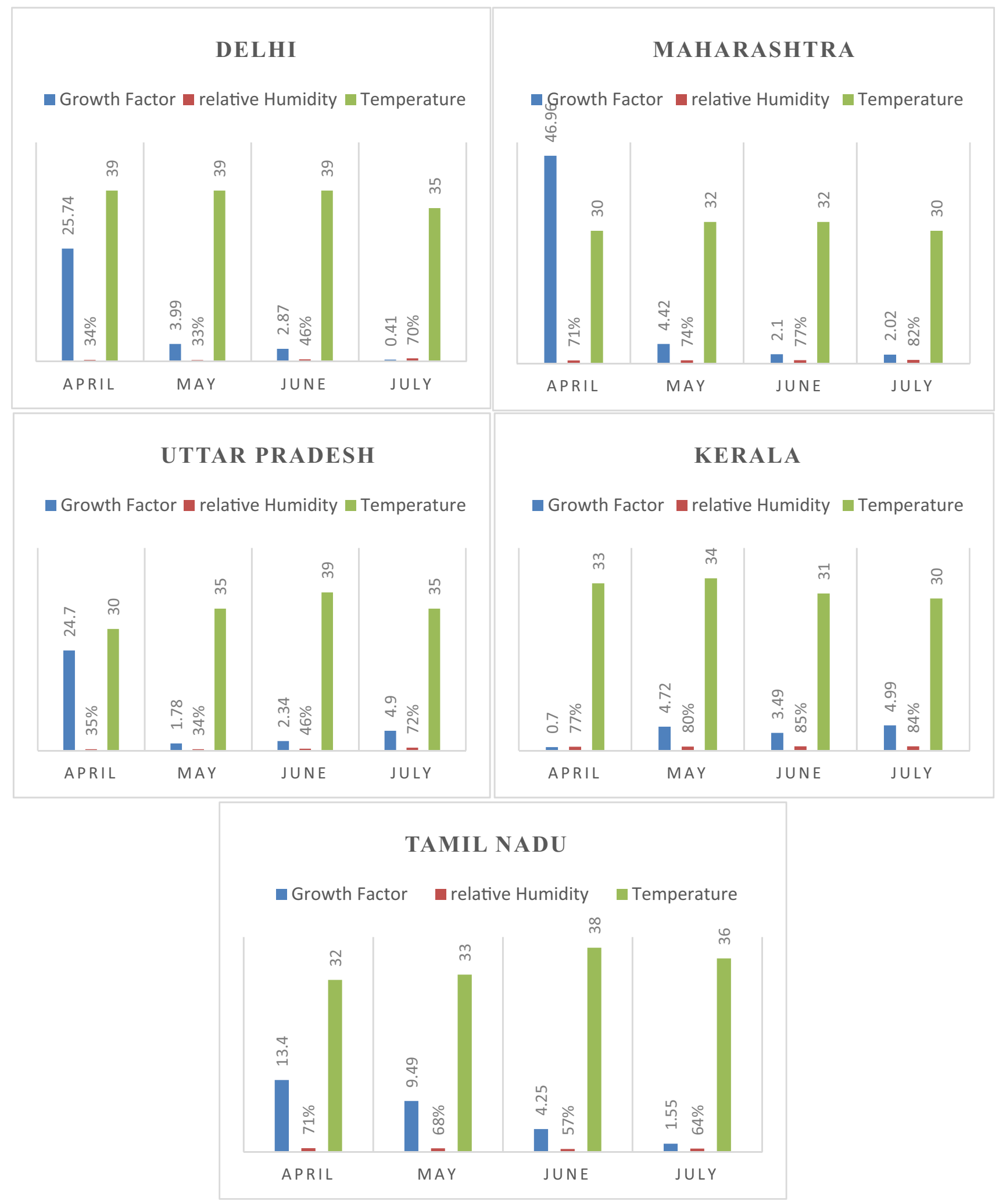

Fig. 9 Effect of temperature and relative humidity on growth factor in different states

in Fig. 8. But, this situation cannot taken as the relaxing phase because as per the investigations on the exponential trend as discussed, if truly followed then in a time span of only one month India shall soon touch the same number of confirmed cases as of Spain today which reflects a devastating and worrisome state. Also, a significant rise in 

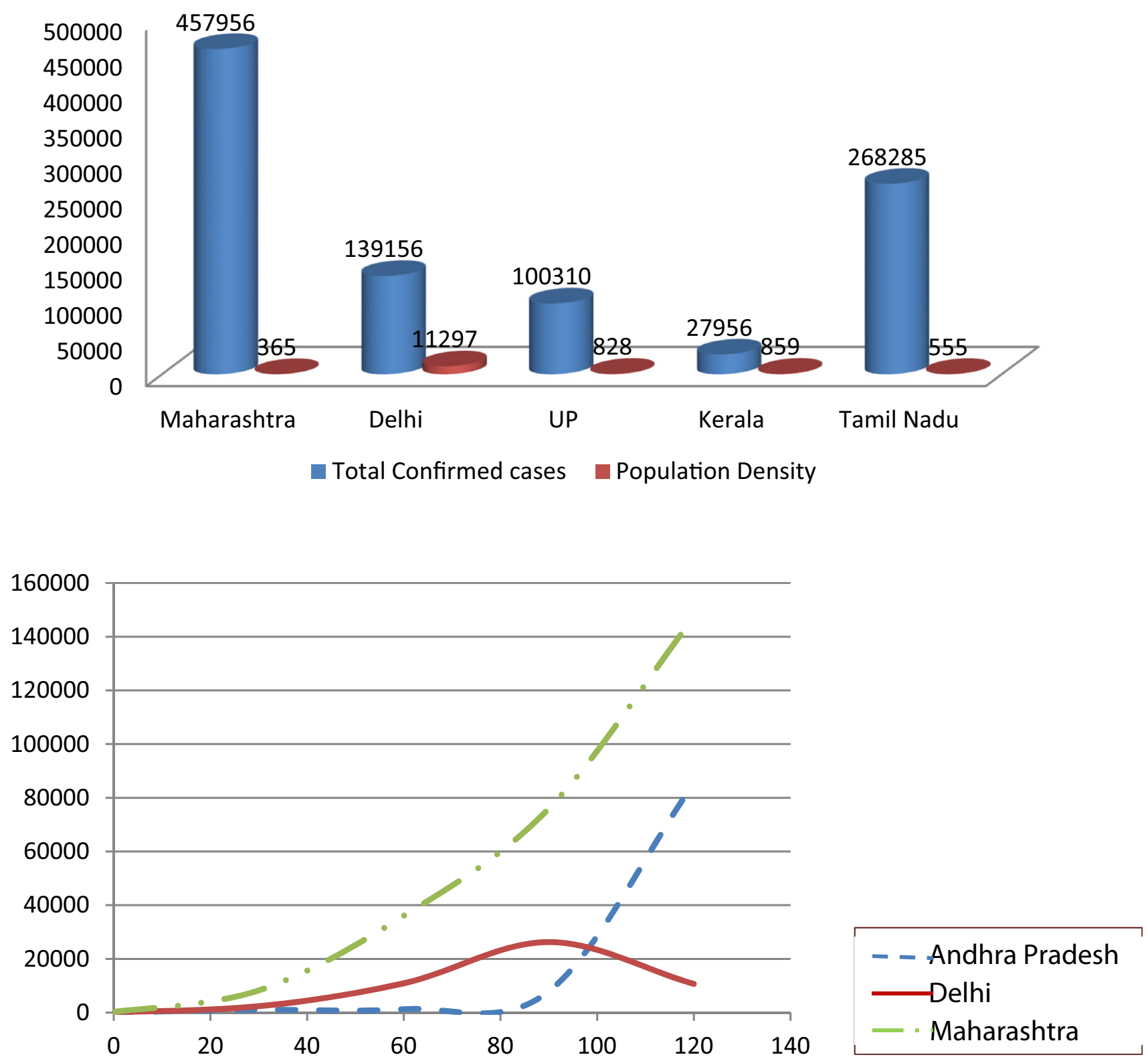

Fig. 10 Correlation of number of active cases and population density

number of confirmed cases as on March 30, 2020, shows an alarming trend of an increasing incidence largely following exponential growth.

The advisories issued to shut down all educational institutions, gyms, museums, cultural and social centers, and theaters are the need of the hour that has taken the shape of complete lockdown of the nation from March 22, 2020 , in response to large-scale transmission of COVID19. In addition, the efforts need to edge the spread of the virus to stage three and emphasize on prevention of unprecedented public health devastation in India. This can be achieved only if efforts are applied in the direction of flattening the transmission curve and limit the exponential movement of the growth curve. However, one of the supporting pillars in the same is to promote maintaining physical distancing of people by all means.

The galvanization of government plays an important role in such epidemics. India has $37 \%$ of its household that depends on labor as their major source of income. In many of the resource-limited areas of the country where majority of the population is poor and survives on daily wages, the provision of testing capacities is often limited to reference laboratories that takes time in delivering of the clinical report, and hence, the chances of transmission of infection, 
if present, increase during the incubation period making the major population of the area at risk. Also the present data do not show an excessively appealing recovery rate that can be due to late diagnosis of the disease and so availability of resources is the need of the hour.

However, at this stage of infection in India, hospital beds, masks, and sanitizers cannot be counted as separate commodities and a shortage of the two resources is a likely predictive stage. Their requirements compound each other's severity. If mask becomes a scarce resource for everyone, then the doctors and nurses may start dropping from the workforce for days at a time. This will lead to intense shortage of the staff that will further make the challenge as multifaceted. Similarly, an analysis of the availability and use ratio of the equipment can also be drawn out for thousands of medical devices, supplies, services, and usability ranging from simple products and instruments of saline drips, sanitizers, hospital staples to even complex equipment like ventilators or extracorporeal membrane oxygenation devices. This reflects as to how the availability of required number of equipment and other necessities can act as a limitation to compound one another in reducing the number of alternatives available to clinicals.

From the above discussion, it can be concluded that a single factor does not control the spread of virus. The analysis shows that factors such as population density, education, cultural norms around the widespread wearing of masks, use of sensitizers, social distancing with the possibility that factors such as climatic condition (hot and humid weather) may also play a role in lowering the growth rate of virus. However, measure of population density may play an important role in the rate of spread, because with dense population norms of social distancing are not completely followed this will lead to the increase in the growth rate.

Also, the metropolitan size, education, and demographic factors also play a significant role in the spread of virus and its control. A widespread adoption of social distance practice throughout the state can play key role in improving the health standards of the people in areas of dense population. We believe that this may because of other significant factors, principally cultural norms around the widespread wearing of masks, with the possibility that factors such as climate may also play a role. However, we believe that a (correctly defined) measure of population density may play an important role in understanding the rate of spread, and should feature in the discussion when making comparisons of the final outcome of the pandemic within continents.

Though the epidemiological study, as of April 03, 2020, data deny of any community spread, the logarithmic scale predicts the outbreak in near future. The present research provides a firm foundation for future work in these areas. The suppression of the spread of virus can be achieved if stringent measures are taken and maintained sincerely.

\subsection{Future Prospects}

Here we see the pattern for incidence (occurrence of new cases) which deals with the transition from health to disease. In the second part of paper, studies with respect to prevalence shall be conducted that will focus on the period of time that a person lives with a disease.

Also, stability of the model will be studied considering various factors affecting the transmission of disease and preventing it to spread worldwide.

The further studies of analysis of the outbreak of COVID-19 in different states in India with upcoming data using infectious disease dynamics model and investigations are under process to be published in the second part of paper.

Acknowledgements The authors extend their appreciation to the Deanship of Research Cell at Galgotias College of Engineering and Technology for its contribution in providing resources for data compilation.

\section{References}

[1] X. Yang, Y. Yu, J. Xu, et al., Clinical course and outcomes of critically ill patients with SARS-CoV-2 pneumonia in Wuhan, China: a single-centered, retrospective, observational study. Lancet Respir. Med., 2 (2020) 1-7.

[2] J.W.M. Chan, C.K. Ng, Y.H. Chan, et al., Short term outcome and risk factors for adverse clinical outcomes in adults with severe acute respiratory syndrome (SARS). Thorax, 58 (2003) 686-689.

[3] Q. Li, X. Guan, P. Wu, et al., Early transmission dynamics in Wuhan, China, of novel coronavirus-infected pneumonia. N. Engl. J. Med., 382(13) (2020) 1199-1207.

[4] S.R. Weiss and J.L. Leibowitz, Coronavirus pathogenesis. Adv. Virus Res. 81 (2011) 85-164.

[5] P.S. Masters and S. Perlman, Coronaviridae. In: D.M. Knipe and P.M. Howley, eds. Fields virology, 6th ed. Lippincott Williams \& Wilkins, Philadelphia (2013) pp. 825-858.

[6] S. Su, G. Wong, W. Shi, et al., Epidemiology, genetic recombination, and pathogenesis of coronaviruses. Trends Microbiol., 24 (2016) 490-502.

[7] J. Cui, F. Li and Z.L. Shi, Origin and evolution of pathogenic coronaviruses. Nat. Rev. Microbiol., 17 (2019) 181-192.

[8] N.S. Zhong, B.J. Zheng, Y.M. Li, et al., Epidemiology and cause of severe acute respiratory syndrome (SARS) in Guangdong, People's Republic of China, in February, 2003. Lancet, 362 (2003) 1353-1358.

[9] C. Drosten, S. Gunther, W. Preiser, et al., Identification of a novel coronavirus in patients with severe acute respiratory syndrome. N. Engl. J. Med., 348 (2003) 1967-1976.

[10] V.J. Munster, M. Koopmans, N. van Doremalen, D. van Riel and E. de Wit, A novel coronavirus emerging in China-key questions for impact assessment. N. Engl. J. Med., 382 (2020) 692-694. 
[11] L.T. Phan, T.V. Nguyen, Q.C. Luong, et al., Importation and human-to-human transmission of a novel coronavirus in Vietnam. N. Engl. J. Med., 382 (2020) 872-874.

[12] C. Rothe, M. Schunk, P. Sothmann, et al., Transmission of 2019-nCoV infection from an asymptomatic contact in Germany. N. Engl. J. Med., 382(10) (2020) 1-2.

[13] The Novel Coronavirus Pneumonia Emergency Response Epidemiology Team, The epidemiological characteristics of an outbreak of 2019 novel coronavirus disease (COVID-19)-China, 2020. China CDC Wkly., 2 (2020) 1-10.

[14] S. Hoehl, H. Rabenau, A. Berger, et al., Evidence of SARS$\mathrm{CoV}-2$ infection in returning travelers from Wuhan, China. N. Engl. J. Med., 382(13) (2020) 1-2.

[15] Novel Coronavirus (2019-nCoV) Situation report-10, WHO (2020).

[16] https://www.indiatoday.in/india/story/coronavirus-in-indiatracking-country-s-first-50-covid-19-cases-what-numbers-tell1654468-2020-03-12.

[17] https://www.cdc.gov/coronavirus/2019-ncov/faq.html.

[18] Novel coronavirus disease, situation update report -7 , WHO (2020).

[19] https://economictimes.indiatimes.com/news/politics-and-nation/ coronavirus-positive-cases-in-maharashtra-jump-to-74/article show/74756491.cms.

[20] https://www.who.int/india/emergencies/novel-coronavirus-2019.
[21] Ministry of Health and Family Welfare, Government of India. https://www.mohfw.gov.in/.

[22] F. Wu, A. Wang, M. Liu, et al., Neutralizing antibody responses to SARS-CoV-2 in a COVID-19 recovered patient cohort and their implications, medRxiv, (2020). https://doi.org/10.1101/ 2020.03.30.20047365.

[23] Y. Ma, Y. Zhao, J. Liu, X. He, B. Wang, S. Fu, J. Yan, J. Niu, J. Zhou and B. Luo, Effects of temperature variation and humidity on the death of COVID-19 in Wuhan, China. Sci. Total Environ., 724 (2020) 138226.

[24] C.H. Jon Brassey, R. Mahtani Kamal and K.A. Jeffrey, Do weather conditions influence the transmission of the coronavirus (SARS-CoV-2) (2020). https://www.cebm.net/wp-content/uploads/ 2020/03/Do-weather-conditions-influence-the-transmission-of-thenovel-coronavirus-2019-nCoV_.pdf.

[25] A.W.H. Chin, J.T.S. Chu, M.R.A. Perera, K.P.Y. Hui, H. Yen, M.C.W. Chan, M. Peiris and L.L.M. Poon, Stability of SARSCoV-2 in different environmental conditions. Lancet Microbe (2020). https://doi.org/10.1016/s2666-5247(20)30003-3.

[26] https://www.medicalnewstoday.com/articles/how-humidity-mayaffect-covid-19-outcome\#4060\%-humidity-may-be-ideal.

Publisher's Note Springer Nature remains neutral with regard to jurisdictional claims in published maps and institutional affiliations. 